\section{JTI}

JOURNAL OF

TRAUMA AND INJURY

\title{
Experience of Penetrating Gunshot Wound on Head in Korea
}

\author{
Hong Rye Kim, M.D. ${ }^{1}$, Seung Je Go, M.D. ${ }^{2}$, Young Hoon Sul, M.D. ${ }^{2}$, \\ Jin Bong Ye, M.D. ${ }^{2}$, Jin Young Lee, M.D. ${ }^{2}$, Jung Hee Choi, M.D. ${ }^{3}$, \\ Seoung Myoung Choi, M.D. ${ }^{4}$, Yook Kim, M.D. ${ }^{5}$, Su Young Yoon, M.D. ${ }^{6}$ \\ Departments of ${ }^{1}$ Neurosurgery, ${ }^{2}$ Trauma Surgery, ${ }^{3}$ Anesthesiology, ${ }^{4}$ Orthopedic Surgery, \\ ${ }^{5}$ Radiology, and ${ }^{6}$ Thoracic Surgery, Chungbuk National University Hospital, Cheongju, \\ Korea
}

Craniocerebral gunshot injuries (CGIs) are extremely seldom happened in Korea because possession of individual firearm is illegal. So, CGIs are rarely encountered by Korean neurosurgeons or Korean trauma surgeons, though in other developing countries or Unites states of America their cases are indefatigably increasing. Management goal should focus on early aggressive, vigorous resuscitation. The treatments consist of immediate life salvage through correction of coagulopathy, intracranial decompression, prevention of infection and preservation of nervous tissue. There have been few studies involving penetrating CGIs in Korea. Here we present a case of penetrating gunshot wound in Korea. We present a 58-year-old man who was unintentionally shot by his colleague with a shotgun. The patients underwent computed tomography (CT) for assessment of intracranial injury. The bullet passed through the left parietal bone and right lateral ventricle and exited through the posterior auricular right temporal bone. After CT scan, he arrested and the cardiopulmonary resuscitation was conducted immediately. But we were unable to resuscitate him. This case report underscores the importance of the initial clinical exam and CT studies along with adequate resuscitation to make the appropriate management decision. Physicians should be familiar with the various injury patterns and imaging findings which are poor prognostic indicators.

Keywords: Wounds, Penetrating; Wounds, Gunshot; Craniocerebral trauma

\section{INTRODUCTION}

Craniocerebral gunshot injuries (CGI) are increasingly encountered by physicians especially in developing countries [1] or the United States of America [2]. However, they 
are extremely seldom happened in Korea because possession of individual firearm is illegal. So CGIs are rarely encountered by Korean neurosurgeons or Korean trauma surgeons. CGIs are the most lethal of all firearm injuries, with reported survival rates of only $7 \%$ to $15 \%$ [3].

About $90 \%$ of the time, the victims die before arriving at the hospital and for those who survive, 50\% die in the emergency room [4]. Peak mortality from CGI happens at the scene or within 3 hours of injury [5]. We describe a case of a patients visiting to our hospital with a transcranial penetrating injury by a gunshot.

\section{CASE REPORT}

\section{History and presentation}

A 58-year-old man visited our emergency unit with shotgun wounds. He was on a hunting wild boars when he was unintentionally shot in his left head and left arm by his colleague with a shotgun. He was brought to our hospital by helicopter. By the time the ambulance worker reached at the scene of the accident, his pulse and breathing was stable. But 5 minutes before the helicopter arrived at our hospital, his pulse became low and weak, so we did cardiopulmonary cerebral resuscitation (CPCR) for moving the patient from the helicopter to the emergency room. About 30 minutes after CPCR, the return of spontaneous circulation was achieved. On a physical examination, his both pupils were fixed and dilatated with a Glasgow coma scale (GCS) score of III. Inspection of the head revealed that the bullet appeared to penetrate the left parietal region and stop at the posterior auricular area (Fig. 1).

\section{Imaging}

After the vital sign had stabilized, we performed the head computed tomography (CT). The CT demonstrated that the bullet passed through the left parietal bone and transversed frontal lobe, coursing through right lateral ventricle, and exited through the posterior auricular right temporal bone (Fig. 2). The bullet was under postauricular skin. the Imaging showed scattered fragments of the bullet mainly in the right frontal lobe. Diffuse subarachnoid hemorrhage and intraventricular hemorrhage was present within the both lateral ventricles. After CT scan, he arrested again and CPCR was conducted immediately. But we were unable to resuscitate him this time.
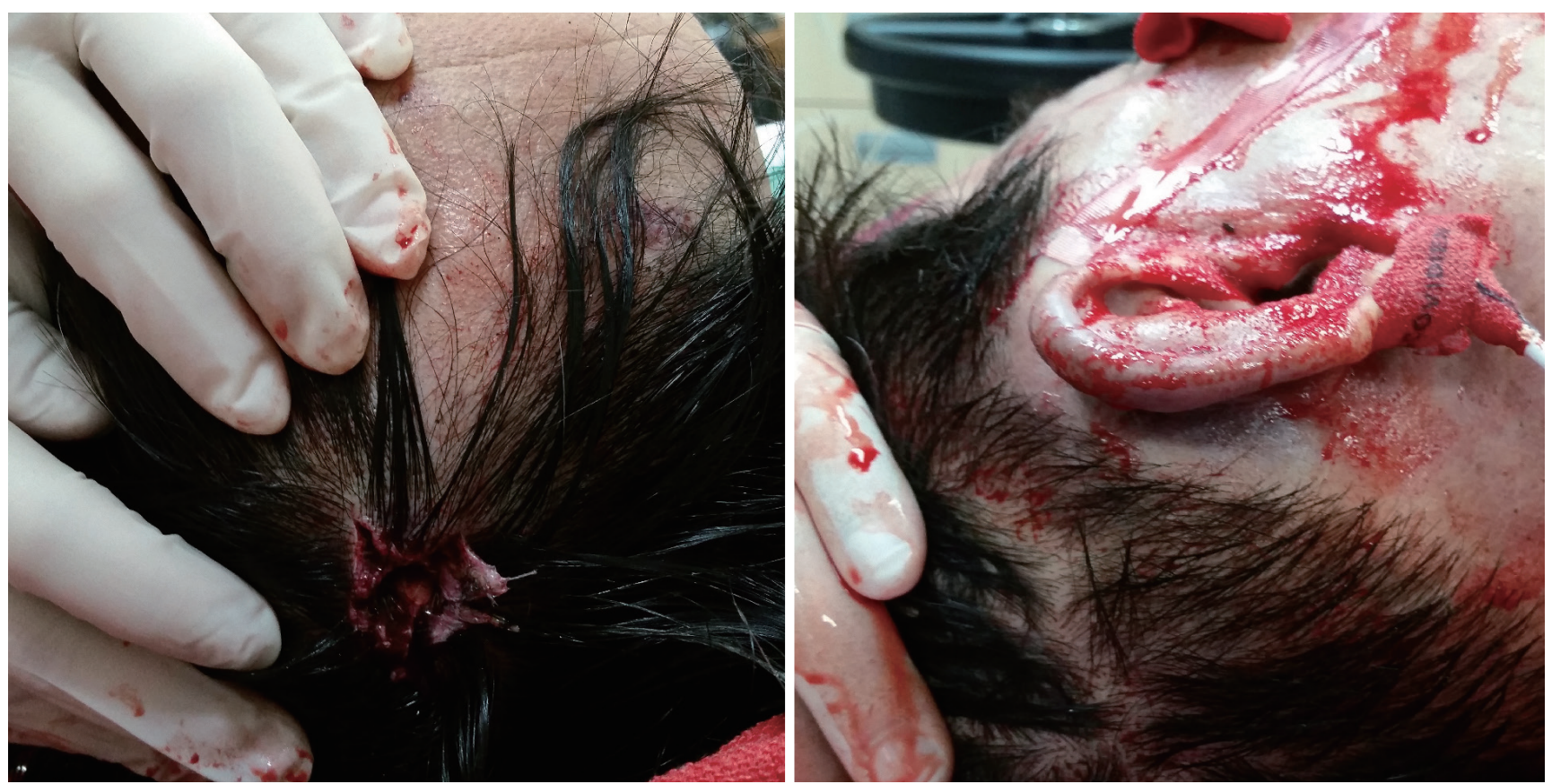

Fig. 1. The bullet penetrated the left parietal region and stopped at the posterior auricular area. 


\section{JTI}

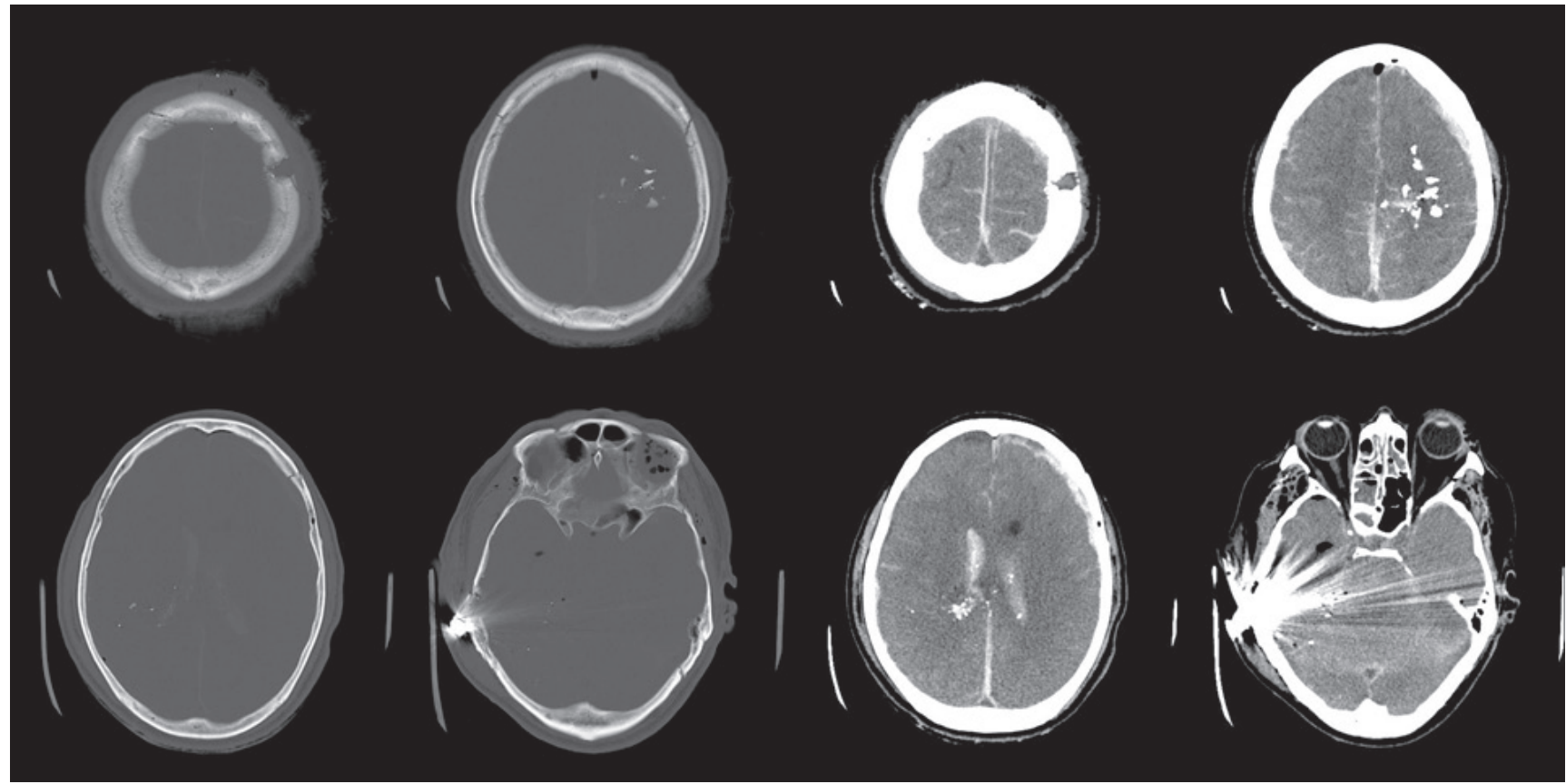

Fig. 2. Brain computed tomography (CT) scan of the patient. The bullet passed through the left parietal bone and transversed frontal lobe, coursing through right lateral ventricle and exited through the posterior auricular right temporal bone.

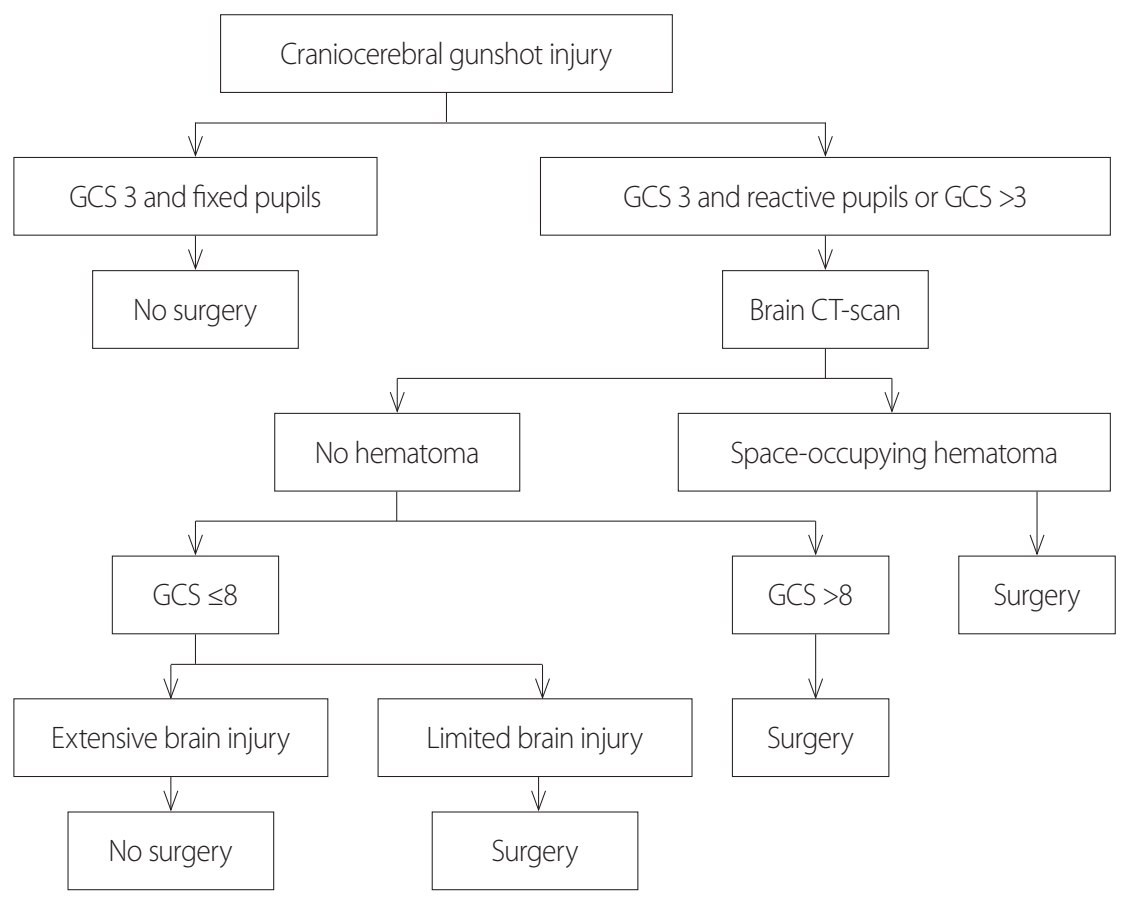

Fig. 3. Management guideline for craniocerebral gunshot injury. GCS: Glasgow coma scale, CT: computed tomography. 


\section{DISCUSSION}

Penetrating brain injuries involving foreign bodies are less prevalent than closed head injuries but carry a worse prognosis [6,7]. Especially, missile injuries have impact velocities of greater than 120 meters per second, cause damage with thermal and kinetic injuries, and thus are associated with a higher morbidity and mortality [8]. Management goals should focus on early aggressive, vigorous resuscitation and correction of coagulopathy. Thorough examination is necessary for any patient with scalp wound, as penetrating foreign bodies may be obvious or occult. Our case is an example of this as the bullet had located under postauricular skin, did penetrate the temporal bone but not the skin. Those with stable vital signs undergo brain CT scan [9]. Surgical management of these patients is controversial. Tsuei et al. [10] suggested an algorithm for CGIs, in which according to GCS and pupilary reactivity, the decision to perform or not surgery is taken (Fig. 3). When the surgical approach is needed, prompt removal of the entire foreign body, removal of bone fragments, focal debridement, decopression of neurovascular structures, hemostasis, and dural repair are key goals of surgery $[6,7,11]$. Direct visualization of an intracranial object during removal is ideal so that bleeding can be controlled if a tamponade effect is lost and also that any retrained fragments may be seen and subsequently removed [8]. Proper imaging preoperatively is imperative to identify any injured vessels and potential tamponade effect before removing an object [12].

Head CT remains the most valuable study for initial evaluation of foreign objects and assessing the extent of injury. Plain radiographs are useful for the intracranial localization of metallic foreign bodies when CT scans are limited by artifact $[6,11]$. When there is a high index of suspicion for vascular injury, at least CT angiography, but preferably digital subtraction angiography, may be necessary before surgery for operative planning $[6,7]$. In CGI populations, features associated with higher risk of vascular injury include orbitofacial or pterional penetraitingbrain injury, presence of intracranial hematoma, and fragments crossing 2 or more dural compartments [6,7]. Angiography is also indicated after surgery to monitor for vascular complications such as traumatic intracrani- al aneurysm and pseudoaneurysm formation. It is also strongly recommended in cases of delayed or unexplained subarachnoid or intracranial hemorrhage [6,7].

There is a high risk of intracranial infection in patients with CGIs, and it probably results from the presence of contaminated foreign bodies (i.e., metallic fragments, skin pieces, hair, and osseous fragments) that penetrate the skull and touch brain tissue following the projectile trajectory. After the introduction of antibiotic therapy, incidence of specific lesions such as brain abscesses associated with CGIs decreased from 8.5\% to $1.6-3.1 \%$ [13]. Most posttraumatic infections caused by CGIs appear early after the wound: 55\% during the first 3 weeks and $90 \%$ before the 6 th week [13], however, some brain abscesses have been described 15 years after the trauma [14]. Broad-spectrum antibiotics capable of crossing the bloodbrain barrier and prompt foreign body removal are indicated $[7,12]$. Staphylococcus aureus is the most frequently encountered pathogen, though gram-negative bacteria are also common and anaerobic bacteria are also occasionally seen [7]. Tetanus vaccination should also be administered as indicated [11].

Intracranial pressure (ICP) monitoring has been well documented to be an important predictor of prognosis in severe non-penetrating traumatic brain injury (TBI) as intracrebral hemorrhage (ICH) is clearly associated with worse recovery and optimum control of elevated ICP leads to a better outcome. The available data suggest a higher frequency of raised ICP in CGI patients, and when present, raised ICP is documented to be a predictor of worse prognosis [7]. In cases, where ICP is monitored and ICH is present, treatment measures are the same, which are used in non-penetrating TBI, i.e., sedatives, mannitol, CSF drainage, high-dose barbiturates, and decompressive craniectomy [15].

Approximately $30-50 \%$ of patients with penetrating brain injury develop seizures [6,7]. Between $4 \%$ and 10\% have their first seizure within the first week of injury, and $80 \%$ of patients have a seizure during the first 2 years $[7,12]$. Antiepiletic medication has been shown to prevent the occurrence of early but not late seizures. For this reason, prophylaxis is recommended for the first 7 days after injury $[6,7,12]$.

There have been few recent studies involving CGIs, and 
most studies have been restricted to small numbers of patients, which do not allow for adequate prediction of mortality. While an individualized approach is certainly necessary for patients with CGIs, certain management principles apply to nearly every case. These include maintaining a high suspicion for intracranial injury when the presentation is occult, transfer to a neurosurgical and neuroendovascular center with head and neck surgery available, and prompt removal of the object when presentation is acute. It is important to recognize the role of vigorous and intense resuscitation but always evaluated together with predictors of mortality. Head CT is the most sensitive initial study and should often be followed with CT angiography or digital subtraction angiography to assess vascular injury. Goal of surgery should include removal of the object in a way that minimizes collateral damage, debridement of bone or object fragments, and hemostasis. Direct visualization of object and extent of injury is preferred in most cases. Postoperative imaging and follow-up is imperative to assess for complications such as delayed vascular injury and abscess formation, as these can present in a delayed fashion. Postprocedural infection, seizures, hemorrhage, and ICP elevation are key areas for prophylaxis and management. It is necessarily urgent to continue promoting research in CGIs, looking impact positively the quality of life for those who survive.

\section{REFERENCES}

1. Alvis-Miranda HR, Adie Villafañe R, Rojas A, Alcala-Cerra G, Moscote-Salazar LR. Management of craniocerebral gunshot injuries: a review. Korean J Neurotrauma 2015;11:35-43.

2. DeCuypere M, Muhlbauer MS, Boop FA, Klimo P Jr. Pediatric intracranial gunshot wounds: the Memphis experience. J Neurosurg Pediatr 2016;17:595-601.

3. Selden BS, Goodman JM, Cordell W, Rodman GH Jr, Schnitzer PG. Outcome of self-inflicted gunshot wounds of the brain. Ann Emerg Med 1988;17:247-53.

4. Shaffrey ME, Polin RS, Phillips CD, Germanson T, Shaffrey
CI, Jane JA. Classification of civilian craniocerebral gunshot wounds: a multivariate analysis predictive of mortality. J Neurotrauma 1992;9 Suppl 1:S279-85.

5. Levy ML, Masri LS, Lavine S, Apuzzo ML. Outcome prediction after penetrating craniocerebral injury in a civilian population: aggressive surgical management in patients with admission Glasgow Coma Scale scores of 3, 4, or 5. Neurosurgery 1994;35:7784; discussion 84-5.

6. Gutiérrez-González R, Boto GR, Rivero-Garvía M, Pérez-Zamarrón A, Gómez G. Penetrating brain injury by drill bit. Clin Neurol Neurosurg 2008;110:207-10.

7. Kazim SF, Shamim MS, Tahir MZ, Enam SA, Waheed S. Management of penetrating brain injury. J Emerg Trauma Shock 2011;4:395-402.

8. Zyck S, Toshkezi G, Krishnamurthy S, Carter DA, Siddiqui A, Hazama A, et al. Treatment of penetrating nonmissile traumatic brain injury. Case series and review of the literature. World Neurosurg 2016;91:297-307.

9. Joseph B, Aziz H, Sadoun M, Kulvatunyou N, Pandit V, Tang A, et al. Fatal gunshot wound to the head: the impact of aggressive management. Am J Surg 2014;207:89-94.

10. Tsuei YS, Sun MH, Lee HD, Chiang MZ, Leu CH, Cheng WY, et al. Civilian gunshot wounds to the brain. J Chin Med Assoc 2005;68:126-30.

11. Gökçek C, Erdem Y, Köktekir E, Karatay M, Bayar MA, Edebali N, et al. Intracranial foreign body. Turk Neurosurg 2007;17:1214.

12. Williams JR, Aghion DM, Doberstein CE, Cosgrove GR, Asaad WF. Penetrating brain injury after suicide attempt with speargun: case study and review of literature. Front Neurol 2014;5:113.

13. Hagan RE. Early complications following penetrating wounds of the brain. J Neurosurg 1971;34(2 Pt 1):132-41.

14. Gönül E, Baysefer A, Kahraman S, Ciklatekerlio lu O, Gezen F, Yayla O, et al. Causes of infections and management results in penetrating craniocerebral injuries. Neurosurg Rev 1997;20:17781.

15. Alvis-Miranda H, Castellar-Leones SM, Moscote-Salazar LR. Decompressive craniectomy and traumatic brain injury: a review. Bull Emerg Trauma 2013;1:60-8. 